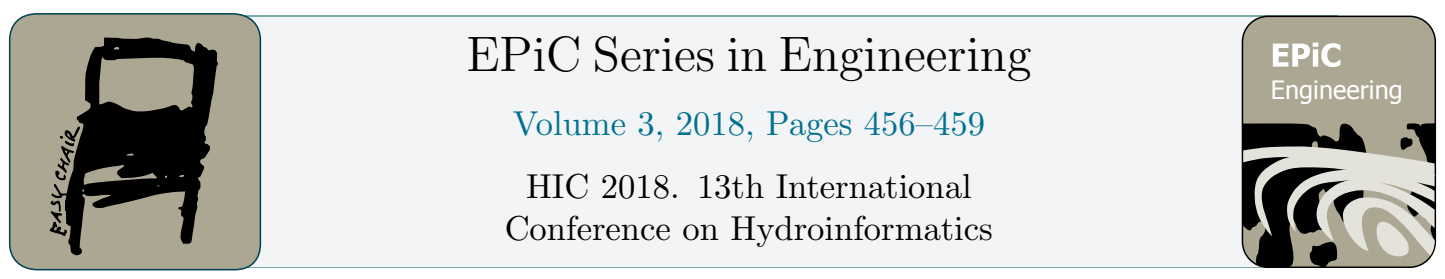

\title{
Physical Habitat Simulation with ANFIS Method
}

\author{
Sung-Uk Choi ${ }^{1 *}$, Dongkyun $\mathrm{Im}^{2}$, Seung Ki Kim ${ }^{1}$ \\ ${ }^{1}$ Yonsei University, Seoul, Korea \\ ${ }^{2}$ Korea Engineering \& Consulting Association, Seoul, Korea \\ schoi@yonsei.ac.kr, dongkyun@kenca.or.kr, seunggi@yonsei.ac.kr
}

\begin{abstract}
This study presents physical habitat simulations to investigate the impact of weir removal on the composition of fish community in a river. The study site is a $900 \mathrm{~m}$ long reach in the Gongneung-cheon Stream in Korea, at the middle of which the weir was located. Fish monitoring revealed that lentic fishes were dominant before the weir removal, however lotic fishes became dominant after the weir removal. The ANFIS method, a data-driven method, was used for the habitat simulation with River2D for hydraulic simulation. The distribution of highly suitable portion for each fish species were given before and after weir removal. It was shown that the physical habitat simulation successfully predicts the change in the composition of fish community after the weir removal. The simulated results were compared with those from the knowledgebased model.
\end{abstract}

\section{Introduction}

A conventional method for the habitat simulation is a habitat suitability index model, a knowledgebased approach. The habitat suitability curve is a representative habitat suitability index model. However, this method is often criticized due to that it is not capable of accounting for the correlation between habitat variables and the spatial connectivity between habitats. In addition, the subjective opinions from the experts can easily affect this method. An alternative is the data-driven approach such as ANN model, fuzzy logic, GEP model, and ANFIS method.

This study investigated the impact of weir removal on the composition of the fish community using the physical habitat simulation. The River2D model and the ANFIS method were used for hydraulic and habitat simulations, respectively. The study area is a $900 \mathrm{~m}$ long reach in the Gongneung-cheon Stream in Korea, and the Gongneung Weir-2 was located at the middle of the reach. The Gongneung Weir-2 was built for irrigation in the 1970s and was removed in 2006. Removal of this weir was made after agreement between the local government and residents. Field monitoring indicated that five fish species were dominant and they account for more than $80 \%$ of the total fish community. The purpose 
of this study was to predict the change in the composition of the fish community after the weir removal using the physical habitat simulation. The distributions of highly suitable portion (HSP) of each fish species before and after are given and are compared with the result from the knowledge-based model.

\section{Material and Methods}

The study site is a $900 \mathrm{~m}$ long reach of the Gongneung-cheon Stream in Korea. This stream, a major tributary of the Han River, is $47 \mathrm{~km}$ long and has a watershed area of $260.0 \mathrm{~km}^{2}$. The mean annual precipitation of the watershed is 1,384 mm (Ministry of Land, Transport and Maritime Affairs, 2012). The discharges for the drought flow $\left(\mathrm{Q}_{355}\right)$, low flow $\left(\mathrm{Q}_{275}\right)$, normal flow $\left(\mathrm{Q}_{185}\right)$, and averaged-wet flow $\left(\mathrm{Q}_{95}\right)$ are $0.28,0.51,0.91$, and $1.73 \mathrm{~m}^{3} / \mathrm{s}$, respectively (Korea Institute of Construction and Technology, 2008). The Gongneung Weir-2, which is $1.5 \mathrm{~m}$ high, $75 \mathrm{~m}$ wide, and 8.8 . $\mathrm{m}$ long, was located at the middle of the study reach. The Gongneung Weir-2 was built in the 1970s to supply irrigation water to the nearby area. However, the weir was left untended for a long time due to the land use change of the neighboring area. On March 2006, the local government and residents agreed to remove the weir, and the removal was made on April 14, 2006.

Fish monitoring was carried out before and after the weir removal. It was found that A. rivularis, $Z$. platyous, $R$. brunneus, A. springeri, and P. esocinus were dominant before the weir removal. These five fish species accounted for more than $80 \%$ of the entire fish community. However, after the removal, the dominance of the fish species changed dramatically. The most dominant fish species after the removal was found to be $R$. brunneus, followed by Z. platyous, $P$. esocinus, A. springeri, and A. rivularis. It is noteworthy that the most dominant fish species changed from a lentic fish (A. rivularis) to a lotic fish ( $R$. brunneus) after the weir removal. This is related to the change in the flow and bed sediment.

In the present study, the River2D was used for the hydraulic simulation. The River2D solves 2D depth-averaged shallow water equations using the finite element method (Steffler and Blackburn, 2002). The shallow water equations are composed of continuity and momentum equations. The solution of the shallow water equations provides flow depth and 2D depth-averaged velocities. The River2D offers both wet and dry solutions, which is required definitely for simulations under low flow conditions.

For habitat simulation, the ANFIS method proposed by Jang (1993) was used. The ANFIS method is a hybrid algorithm that combines the fuzzy logic with the neural network. The ANFIS method has a five-layer architecture, namely, fuzzy layer, product layer, normalized layer, defuzzifier layer, and output layer. Output variables at each layer are calculated with input variables from the previous layer and parameters at each node. The input values of the ANFIS network are velocity, flow depth, and substrate, and the output variables are the composite suitability index (CSI). Four membership functions, namely low, medium, high, and very high, were used for the input values. The Gaussian type of membership function was used.

\section{Results and Discussion}

The HSP distribution for each fish species before the weir removal is given in Figure 1. The figure shows that the HSP for A. rivularis, a lentic fish, is mainly located at the upstream zone of the weir and near the downstream end. Both locations are retention zones is created by weirs. However, the HSPs for such lotic fishes are found downstream of the weir.

Figure 2 shows the distribution of the HSP for each fish species after the weir removal. It turns out that habitats of lotic fishes such as $R$. brunneus and Z. platypus have expanded over the entire study reach. In contrast, the habitat area of lentic fishes decreased significantly. This is due to the change in 
the flow and coarsening of the bed sediment after the weir removal. The figure clearly depicts that the continuity in the lotic ecosystem of the stream is enhanced by the weir removal.

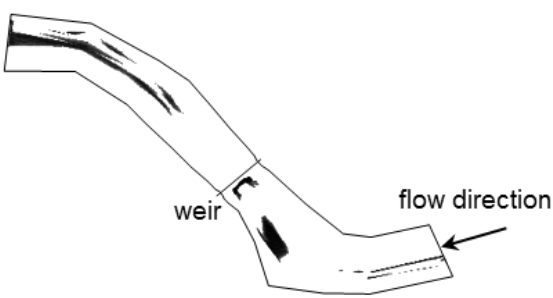

(a) Abbottina rivularis

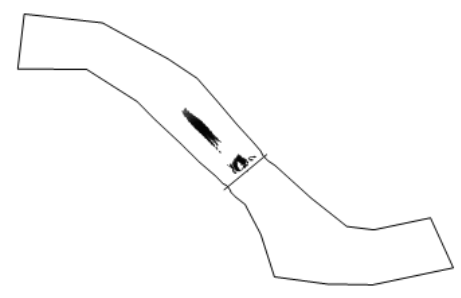

(c) Rhinogobius brunneus

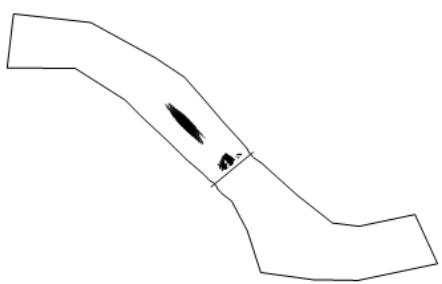

(b) Zacco platypus

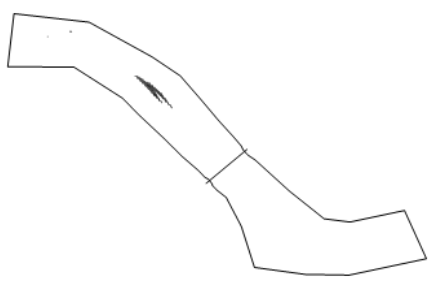

(d) Pseudogobio esocinus

Figure 1: HSP distribution before the weir removal

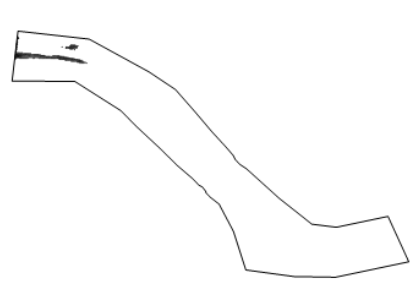

(a) Abbottina rivularis

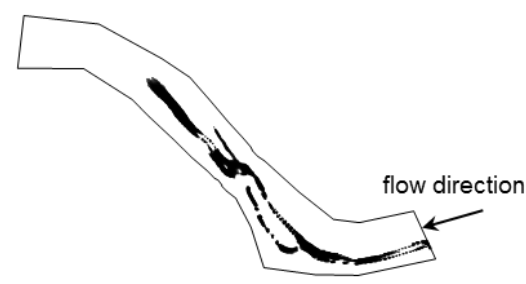

(c) Rhinogobius brunneus

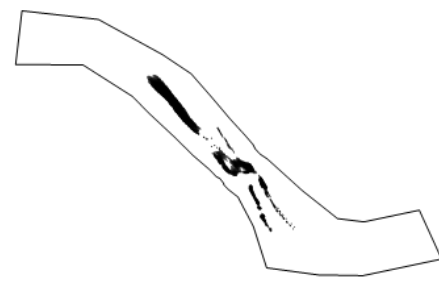

(b) Zacco platypus

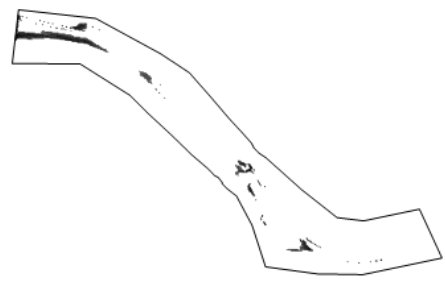

(d) Pseudogobio esocinus

Figure 2: HSP distribution after the weir removal 


\section{Conclusions}

This study presented physical habitat simulations to explore the impact of weir removal in a stream. A $900 \mathrm{~m}$ long reach in the Gongneung-cheon Stream in Korea was selected as a study site. The Gongneung Weir-2 was located at the middle of the study reach. Field monitoring revealed that five fishes were dominant in the study site.

Physical habitat simulations were carried out with the ANFIS method and River2D model for habitat and hydraulic simulations, respectively. The ANFIS method, a data-driven method, predicts directly the habitat quality using the monitoring data. Thus, the method predicts better than the knowledgebased model where the correlation between habitat variables and spatial information of habitats are ignored. The physical habitat simulations resulted in the change in the composition of the fish community after the weir removal. That is, the lotic fishes became dominant after the weir removal, while the lentic fishes were dominant before the weir removal.

\section{Acknowledgements}

This work was supported by the National Research Foundation of Korea (NRF) grant funded by the Korea Government (NRF-2017R1A2A2A05069836).

\section{References}

J-S.R. Jang (1993) ANFIS: Adaptive-network-based fuzzy inference system. IEEE Transactions on Systems, Man and Cybernetics, 23, 665-685.

Korea Institute of Construction and Technology (2008) The stream eco-corridor restoration and water quality improvement by weir removal with its function lost. Ministry of Environment (in Korean).

Ministry of Land, Transport and Maritime Affairs (2012) Basic planning for Gongneung River Watershed. Gyeonggi Province (in Korean).

P. Steffler, J. Blackburn (2002) River2D, "Two-dimensional depth averaged model of river hydrodynamics and fish habitat, Introduction to depth averaged modeling and user's manual. University of Alberta. 